\title{
Exercise lowers blood pressure in university professors during subsequent teaching and sleeping hours
}

This article was published in the following Dove Press journal:

International Journal of General Medicine

18 October 2011

Number of times this article has been viewed

\author{
Fabiana Ribeiro' \\ Carmen S Grubert \\ Campbell' \\ Gisele Mendes' \\ Gisela Arsa ${ }^{1,3}$ \\ Sérgio R Moreira ${ }^{2}$ \\ Francisco M da Silva' \\ Jonato Prestes' \\ Rafael da Costa Sotero' \\ Herbert Gustavo Simões' \\ 'Graduate Program on Physical \\ Education and Health, Catholic \\ University of Brasilia, Brasilia; ${ }^{2}$ Federal \\ University of Vale do São Francisco, \\ Petrolina, ${ }^{3}$ Graduate Program on \\ Physical Education, Nine of July \\ University, São Paulo SP, Brazil
}

Background: University professors are subjected to psychological stress that contributes to blood pressure (BP) reactivity and development of hypertension. The purpose of this study was to investigate the effects of exercise on BP in university professors during teaching and sleeping hours.

Methods: Twelve normotensive professors $(42.2 \pm 10.8$ years, $74.2 \pm 11.2 \mathrm{~kg}, 172.8 \pm 10.4 \mathrm{~cm}$, $20.1 \% \pm 6.7 \%$ body fat) randomly underwent control (CONT) and exercise (EX30) sessions before initiating their daily activities. EX30 consisted of 30 minutes of cycling at $80 \%-85 \%$ of heart rate reserve. Ambulatory BP was monitored for 24 hours following both sessions.

Results: BP increased in comparison with pre-session resting values during teaching after CONT $(P<0.05)$ but not after EX30. Systolic, diastolic, and mean arterial BP showed a more pronounced nocturnal dip following EX30 (approximately $-14.7,-12.7$, and $-9.6 \mathrm{mmHg}$, respectively) when compared with CONT (approximately $-6,-5$ and $-3 \mathrm{mmHg}$ ).

Conclusion: Exercise induced a BP reduction in university professors, with the main effects being observed during subsequent teaching and sleeping hours.

Keywords: post-exercise blood pressure, aerobic exercise, activities of daily living

\section{Introduction}

Nowadays, the high stress levels experienced during certain daily occupational activities have been associated with cardiovascular complications, including increased blood pressure (BP) and mood disturbances..$^{1-3}$ University professors are a professional group that is continuously subjected to a high level of psychological stress ${ }^{4-7}$ which may contribute to the development of hypertension. ${ }^{8,9}$ Previous studies ${ }^{5,10,11}$ have demonstrated that mental stress faced by university professors may lead to chronic psychological disturbance, such as excessive anger, anxiety, irritability, and frustration. These feelings are associated with increased sympathetic tone and BP elevation. ${ }^{8,9}$

Public speeches, such as lectures in class and at meetings, are associated with BP hyperreactivity that may lead to increased risk of hypertension in the longer term. . $^{11,12}$ The relationship between psychological stress, hypertension, and development of several cardiovascular disorders, including coronary artery disease, myocardial infarction, and stroke, are well documented. ${ }^{11-13}$ Several target organs may be affected by chronic BP elevation, ${ }^{14,15}$ with some individuals having a diminished or absent nocturnal dip in BP, who are considered among those with a higher risk for cerebrovascular and cardiovascular events. ${ }^{16,17}$

Encouragingly, even a single exercise session may help subsequent BP control during stressful situations ${ }^{18}$ or activities of daily living. ${ }^{17,19}$ MacDonald et a ${ }^{20}$ observed 
that BP reactivity in hypertensive individuals performing simulated activities of daily living was significantly attenuated by a single session of aerobic exercise.

It has been suggested that the dipping effect of sleep on nocturnal BP can be elicited by chronic exercise, ${ }^{19}$ and a small amount of data has pointed out the benefits of acute aerobic exercise on BP patterns during the night. ${ }^{21}$ To the best of our knowledge, no studies have investigated the benefits of a single "daily dose" of early morning exercise on subsequent BP in university professors frequently subjected to a high level of emotional stress. The aim of the present study was to investigate the acute effects of early morning aerobic exercise on post-exercise BP in university professors during subsequent teaching and sleeping hours. The initial hypothesis was that a single bout of aerobic exercise performed early in the morning would attenuate BP reactivity during teaching and favor a nocturnal dip during sleep.

\section{Materials and methods Participants}

Approval for this study was given by the local Ethics Committee for Human Research at the Catholic University of Brasilia. Twelve university professors (nine male, three female) were recruited by an electronic invitation sent to approximately 100 professors whose teaching activities were undertaken on the same days and time schedule during the week. None of the subjects were hypertensive, smokers, or obese, and were considered to be physically active individuals. Their demographic characteristics included mean (standard deviation) age $42.2 \pm 10.8$ years, mean body weight $74.2 \pm 11.2 \mathrm{~kg}$, height $172.8 \pm 10.4 \mathrm{~cm}$, body fat $20.1 \pm 6.7$, resting heart rate $68.6 \pm 13.8$ beats per minute, and resting systolic/diastolic BP $116.4 \pm 12.9 / 76.2 \pm 10.2 \mathrm{mmHg}$. All subjects had engaged in regular physical activity for at least the previous 6 months (about 20-60 minutes per session either of running, cycling, or resistance exercises, 3-5 days/week). Exclusion criteria were use of medications that would interfere with cardiovascular function, and any neuromuscular, cardiovascular, or any other physiological dysfunction that would limit participation in the study.

\section{Experimental procedures}

After anthropometric measurements and a resting electrocardiogram, the volunteers were randomly assigned to experimental sessions consisting of 30 minutes of exercise (EX30) or control sessions (CONT). The sessions were carried out on different days but at the same time of the day (between 6.30 am and $8 \mathrm{am}$ ) with exercise or control sessions being performed between
$7.00 \mathrm{am}$ and $7.30 \mathrm{am}$. Experimental sessions were separated by at least 48 hours, and each volunteer was instructed to have the same standard breakfast 90 minutes prior to trials.

EX30 consisted of 30 minutes of exercise on a bicycle ergometer (Excalibur ${ }^{\circledR}$, Lode Medical Technology, Groningen, The Netherlands) at an intensity of $80 \%-85 \%$ of heart rate reserve. ${ }^{22}$ In the CONT session, participants remained in a seated position for 30 minutes on a soft chair in an acoustic room free from any noise or transit of people.

\section{Procedures before and after experimental sessions}

Prior to EX30 or CONT, all subjects remained seated at rest for 20 minutes in order to measure BP (by ambulatory BP monitor, Dyna-MAPA ${ }^{\circledR}$, Cardio Sistemas, Sao Paulo, Brazil) and heart rate Polar $^{\circledR}$ S810i, Polar Electro Oy, Kempele, Finland) at 5-minute intervals. During exercise, BP was measured by auscultation using a Tycos ${ }^{\circledR}$ mercury manometer and a Sprague ${ }^{\circledR}$ stethoscope. Following the session, the subjects were allowed to take a shower. Afterwards, the same ambulatory BP monitor was attached for 24-hour BP measurement. The recordings were considered valid for interpretation when at least $90 \%$ were successful. Volunteers were instructed to maintain their normal daily habits and to keep the cuff on their nondominant arm in a relaxed position during the period of BP measurement. Measurements were done at 30-minute intervals throughout the day and at hourly intervals between $11 \mathrm{pm}$ and $7 \mathrm{am}$.

Participants were requested to avoid physical activity and beverages containing caffeine or alcohol for 48 hours before the experimental sessions. Activities of daily living being performed at the times of BP measurement (eg, working, eating, teaching, being in a stressful situation, being asleep or awake) were recorded on a standard report form provided by the researchers. Teaching periods comprised about 3 hours and 15 minutes (195 \pm 20 minutes) and always occurred between 8 am and noon (Table 1).

On the experiment days, participants went to bed on average at $11.24 \mathrm{pm}$ ( \pm 48 minutes), woke up at around $6.42 \mathrm{am}$ ( \pm 43 minutes), and returned to the laboratory for removal of the monitor. Systolic BP, diastolic BP, and mean arterial BP results were collected separately according to teaching hours (morning), working hours during afternoon (eg, class preparation, reading/ studying and test corrections), and night sleeping hours.

\section{Statistical analysis}

Data are presented as the mean \pm standard deviation and absolute variation (ie, delta variation, $\Delta$ ) as indicated by 
Table I General procedures during experimental sessions

\begin{tabular}{|c|c|c|c|c|c|c|c|c|c|c|}
\hline $\begin{array}{l}\text { Breakfast } \\
\text { at home }\end{array}$ & $\begin{array}{l}\text { Arrival } \\
\text { at the } \\
\text { laboratory }\end{array}$ & $\begin{array}{l}\text { Resting } \\
\text { measurements }\end{array}$ & $\begin{array}{l}\text { Exercise } \\
\text { or } \\
\text { control }\end{array}$ & Showering & $\begin{array}{l}\text { MAPA } \\
\text { positioning }\end{array}$ & Teaching & $\begin{array}{l}\text { Lunch } \\
\text { and } \\
\text { post- } \\
\text { lunch }\end{array}$ & $\begin{array}{l}\text { General } \\
\text { activities } \\
\text { of daily } \\
\text { living }\end{array}$ & $\begin{array}{l}\text { Dinner } \\
\text { and } \\
\text { post- } \\
\text { dinner }\end{array}$ & Sleeping \\
\hline $6 \mathrm{am}$ & 6.30 & 6.40 & $\begin{array}{l}7 \mathrm{am} \text { to } \\
7.30 \mathrm{am}\end{array}$ & $\begin{array}{l}7.30 \mathrm{am} \text { to } \\
7.50 \mathrm{am}\end{array}$ & $\begin{array}{l}7.50 \mathrm{am} \text { to } \\
7.55 \mathrm{am}\end{array}$ & $\begin{array}{l}8 \text { am to } \\
\text { noon }\end{array}$ & $\begin{array}{l}\text { Noon } \\
\text { to } 2 \mathrm{pm}\end{array}$ & $\begin{array}{l}2 \mathrm{pm} \text { to } \\
6 \mathrm{pm}\end{array}$ & $\begin{array}{l}6 \mathrm{pm} \text { to } \\
\text { II.30 pm }\end{array}$ & $\begin{array}{l}\text { I } 1.30 \mathrm{pm} \\
\text { to } 7 \mathrm{am}\end{array}$ \\
\hline
\end{tabular}

variation between the pre- and post-experimental periods of recovery. The Shapiro-Wilk test confirmed normal distribution of the data. Homogeneity of variance was verified by Levene's test. Two-way analysis of variance (CONT versus EX30) for repeated measures with Bonferroni as a post hoc test (Statistica ${ }^{\circledR}$ version 5.0) was applied for comparison within experimental sessions. The level of significance was set at $P<0.05$.

\section{Results}

$\mathrm{BP}$ responses over the 24-hour period following EX30 and CONT are presented in Figure 1. Specifically, the absolute variations $(\Delta)$ in systolic, diastolic, and mean arterial BP at 2-hour intervals during session recovery in relation to baseline are displayed for both EX30 and CONT sessions.

There was a significant treatment $\times$ time interaction $(P<0.03)$, as shown by the protective effect of previous exercise (EX30) on systolic, diastolic, and mean arterial BP responses during the teaching period (8 am to noon), when BP did not increase in relation to baseline following EX30. On the other hand, a treatment $\times$ time interaction was evident for CONT, especially during the first 2 hours of teaching, with a significant BP elevation in relation to baseline $(P<0.01)$. Interestingly, the benefits of previous exercise on subsequent BP measurements were also verified during night sleeping hours (midnight to $6 \mathrm{am}$ ), with a more pronounced nocturnal reduction of systolic, diastolic, and mean arterial BP being observed following EX30 as compared with CONT. In addition, treatment $\times$ time interactions were also evident during the 24-hour measurement, whereby the BP drop was 2-4 times higher during sleep after EX30 in comparison with CONT $(P<0.05)$. It is important to point out that the protective effects following EX30 were also observed during time spent awake in the 24 hours after the experimental session $(P<0.01)$.

\section{Discussion}

This study investigated the effects of 30 minutes of cycle ergometer exercise at $80 \%-85 \%$ of heart rate reserve (EX30) on 24-hour BP in university professors during a typical working day and sleeping time. The main findings were a protective effect on BP during teaching and a more pronounced nocturnal dip in BP during sleeping hours following 30 minutes of exercise, which confirms our initial hypothesis. In contrast, the CONT session did not prevent a BP increase during teaching hours, and the expected physiological dip of systolic and mean arterial BP was unchanged during sleeping hours after CONT.

Studies investigating the effects of exercise performed prior to simulated activities of daily living ${ }^{20}$ and office activities of white collar employees ${ }^{23}$ have revealed significant BP reductions compared with a control day without exercise. Moreover, it has been shown that postexercise BP reduction may be influenced by exercise mode ${ }^{23,24}$ and intensity, ${ }^{21,25,27}$ and may last for several hours after exercise. ${ }^{26,28}$

Similar to the present investigation, Morais et $\mathrm{al}^{24}$ compared the effects of early morning exercise (aerobic versus resistance exercise) on subsequent BP response in individuals with type 2 diabetes. It was observed that postexercise $\mathrm{BP}$ attenuation lasted up to the sleeping hours, with a more pronounced effect of resistance exercise, mainly on the nocturnal BP dip. Jones et $\mathrm{al}^{21}$ showed that 30 minutes of aerobic exercise at $70 \%$ of peak $\mathrm{VO}_{2}$ induced a higher drop in BP during the day and sleeping hours in comparison with exercise performed at $40 \%$ of peak $\mathrm{VO}_{2}$. The higher metabolic and cardiovascular stress induced by resistance exercise or aerobic exercise of a higher intensity would probably account for these findings. Because only one exercise mode and intensity was analyzed in the present study, we do not know if the attenuation of BP during teaching hours would be influenced by exercise mode or intensity.

In spite of the protective effect of exercise on subsequent $\mathrm{BP}$ response during classes, and a significant $\mathrm{BP}$ elevation did occur after CONT, the postexercise BP results obtained from the present investigation did not demonstrate any postexercise decrease in BP in relation to baseline. However, these results are in accordance with those of other investigations regarding the effects of exercise on BP using MAPA analysis over 24 hours, ${ }^{29,30}$ as well as during a 9-hour ${ }^{31}$ and 10-hour period after exercise. ${ }^{32}$ These studies did not confirm 

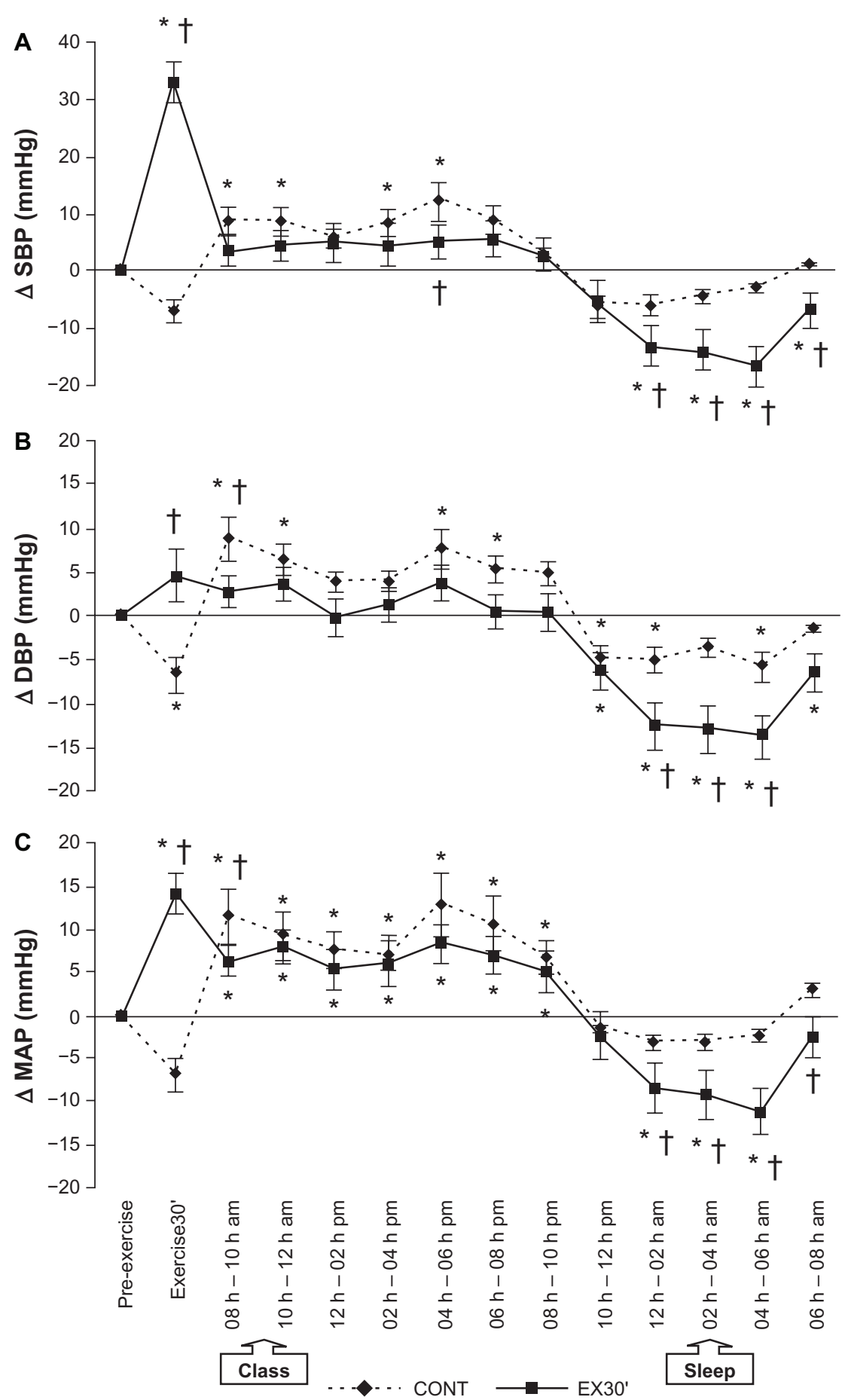

Figure I Change $(\Delta)$ in systolic blood pressure (A), diastolic blood pressure (B) and mean arterial pressure (C) during the 24 hours following exercise (EX30) and control (CONT) sessions.

Note: ${ }^{*} P<0.05$ compared with rest (pre-exercise); ${ }^{\dagger} P<0.05$ compared with CONT session.

Abbreviations: SBP, systolic blood pressure; DBP, diastolic blood pressure; MAP, mean arterial pressure.

a significant postexercise BP decrease during activities of daily living in comparison with baseline resting values. However, while both systolic and diastolic BP increased significantly during teaching after the CONT session in the present study, such reactivity was not observed following
EX30. Moreover, a significant drop during sleeping hours was documented after EX30, but not after CONT, which, in turn, may have clinical relevance.

The attenuation of BP after 30 minutes of aerobic exercise has important implications for the prevention of 
cardiovascular disease and hypertension. Whelton et $\mathrm{al}^{33}$ state that even slight modifications in BP could improve cardiovascular health. Reductions of 3-5 $\mathrm{mmHg}$ in systolic BP can decrease the risk of myocardial infarction by $8 \%-14 \%$ and the risk of coronary disease by $5 \%-9 \%$, as well as reducing all-cause mortality by $4 \%-7 \%$. Similarly, in the present study, 30 minutes of aerobic exercise at $80 \%-85 \%$ of heart rate reserve promoted a lower elevation in BP during the day (3-5 mmHg decrease) compared with no exercise (5-10 $\mathrm{mmHg}$ increase).

Our findings of no post-exercise BP reduction during activities of daily living in relation to pre-exercise resting are not supported by Ciolac et al. ${ }^{28}$ This may be because participants in our present study performed their activities of daily living after exercise, while in the abovementioned study, participants remained in a seated resting position after exercise.

However, it is important to emphasize that 30 minutes of aerobic exercise may lead to cardiovascular benefit, as detected by the lower elevation in BP during teaching and a higher BP drop during sleeping hours, probably allowing better night recovery for the participants. In the longer term, this cardiovascular benefit would prevent the development of diseases such as systemic hypertension and perhaps target organ damage, 3,34 which is prevalent in individuals who are constantly subjected to psychological stress during working activities. ${ }^{1-9}$ The chronic mental stress faced by university professors may lead to feelings of anxiety and frustration, ${ }^{5,10,11}$ which may be associated with increased sympathetic tone and BP elevation. ${ }^{8,9}$ In this sense, due to its lowering effect on post-exercise BP, exercising before daily work would be an interesting strategy for cardiovascular protection in academic professionals.

The mechanisms involved in post-exercise BP reduction have been studied, implicating decreased cardiac output and peripheral vascular resistance ${ }^{35}$ due to lower sympathetic activity inducing transduction of vascular tone, ${ }^{36,37}$ as well as to higher activity of the plasma kallikrein system mediating release of nitric oxide. ${ }^{38-40}$ Alterations in cerebral blood flow induced by exercise has also been proposed as a possible mechanism. ${ }^{41}$ These factors, among others not addressed in the present study, may underlie decreased peripheral vascular resistance. Most of the potential mechanisms, mediated by responses in the autonomic nervous system and vasodilatory molecules would induce either decreased BP after exercise, its attenuation during teaching hours, and perhaps a higher nocturnal dip during sleeping hours in university professors. However, these possible mechanisms still need to be investigated in relation to our findings.

\section{Conclusion}

In summary, 30 minutes of aerobic exercise performed at $80 \%-85 \%$ of the heart rate reserve seemed to elicit both a protective cardiovascular effect during daily teaching and a greater BP decrease during sleeping in university professors. Additional studies investigating the effects of different exercise modes and intensities on post-exercise BP, as well as the underlying mechanisms, are needed.

\section{Disclosure}

The authors report no conflicts of interest in this work.

\section{References}

1. Nordstrom CK, Dwyer KM, Merz CN, Shircore A, Swyer JH. Work-related stress and early atherosclerosis. Epidemiology. 2001;12(2): 180-185.

2. Kivimäki M, Leino-Arjas P, Luukkonen R, Riihimaki H, Vahtera J, Kirjonen J. Work stress and risk of cardiovascular mortality: prospective cohort study of industrial employees. BMJ. 2002;325(7369):857.

3. Flaa A, Mundal HH, Eide I, Kjeldsen S, Rostrup M. Sympathetic activity and cardiovascular risk factors in young men in the low, normal, and high blood pressure ranges. Hypertension. 2006;47(3):396-402.

4. Pedrabissi L, Rolland JP, Santinello M. Stress and burnout among teachers in Italy and France. $J$ Psychol. 1993;127(5):529-535.

5. Chan DW. Hardiness and its role in the stress-burnout relationship among prospective Chinese teachers in Hong Kong. Teaching Teach Educ. 2003;19:381-395

6. Wu S, Li J, Wang M, et al. Intervention on occupational stress among teachers in the middle schools in China. Stress Health. 2006;22(5):329-336.

7. Jin P, Yeung AS, Tang TO, Low R. Identifying teachers at risk in Hong Kong: Psychosomatic symptoms and sources of stress. J Psychosom Res. 2008;65(4):357-362.

8. Rozanski A, Blumenthal JA, Kaplan J. Impact of psychological factors on the pathogenesis of cardiovascular disease and implications for therapy. Circulation. 1999;99(16):2192-2217.

9. Lucini D, Mela GS, Malliani A, Pagani M. Impairment in cardiac autonomic regulation preceding arterial hypertension in humans: insights from spectral analysis of beat-by-beat cardiovascular variability. Circulation. 2002;106(21):2673-2679.

10. Schneider GM, Jacobs DW, Gevirtz RN, O’Connor DT. Cardiovascular haemodynamic response to repeated mental stress in normotensive subjects at genetic risk of hypertension: evidence of enhanced reactivity, blunted adaptation, and delayed recovery. J Hum Hypertens. 2003; 17(12):829-840.

11. Lipp ME, Pereira MM, Justo AP, de Matos TM. Cardiovascular reactivity in hypertensives: differential effect of expressing and inhibiting emotions during moments of interpersonal stress. Span J Psychol. 2006; 9(2):154-161.

12. García-León A, Reyes Del Paso GA, Robles H, Vila J. Relative effects of harassment, frustration, and task characteristics on cardiovascular reactivity. Int J Psychophysiol. 2003;47(2):159-173.

13. Keltikangas-Järvinen L, Heponiemi T. Vital exhaustion, temperament, and cardiac reactivity in task-induced stress. Biol Psychol. 2004;65(2): 121-135.

14. Galetta F, Franzoni F, Plantinga Y, et al. Ambulatory blood pressure monitoring and endothelium-dependent vasodilation in the elderly athletes. Biomed Pharmacother. 2006;60(8):443-447.

15. Su TC, Lee YT, Chou S, et al. Twenty-four-hour ambulatory blood pressure and duration of hypertension as major determinants for intimamedia thickness and atherosclerosis of carotid arteries. Atherosclerosis. 2006;184(1):151-156 
16. Higashi Y, Nakagawa K, Kimura M, et al. Circadian variation of blood pressure and endothelial function in patients with essential hypertension: a comparison of dippers and non-dippers. J Am Coll Cardiol. 2002; 40(11):2039-2043.

17. Liu M, Takahashi H, Morita Y, et al. Non-dipping is a potent predictor of cardiovascular mortality and is associated with autonomic dysfunction in haemodialysis patients. Nephrol Dial Transplant. 2003;18(3): 563-569.

18. Brownley KA, Hinderliter AL, West SG, Girdler SS, Sherwood A, Light KD. Sympathoadrenergic mechanisms in reduced hemodynamic stress responses after exercise. Med Sci Sports Exerc. 2003;35(6): 978-986.

19. Manfredini F, Malagoni AM, Mandini S, et al. Sport therapy for hypertension: why, how, and how much? Angiology. 2009;60(2):207-216.

20. MacDonald JR, Hogben CD, Tarnopolsky MA, MacDougall JD. Post exercise hypotension is sustained during subsequent bouts of mild exercise and simulated activities of daily living. J Hum Hypertens. 2001;15(8):567-571.

21. Jones H, George K, Edwards B, Atkinson G. Exercise intensity and blood pressure during sleep. Int J Sports Med. 2009;30(2):94-99.

22. Jones NL, Makrides L, Hitchcock C, Chypchar T, McCartney. Normal standards for an incremental progressive cycle ergometer test. Am Rev Respir Dis. 1985;131(5):700-708.

23. Mota MR, Pardono E, Lima LC, et al. Effects of treadmill running and resistance exercises on lowering blood pressure during the daily work of hypertensive subjects. J Strength Cond Res. 2009;23(8):2331-2338.

24. Morais PK, Campbell CS, Sales MM, et al. Acute resistance exercise is more effective than aerobic exercise for 24-h blood pressure control in type 2 diabetics. Diabetes Metab. 2011;37(2):112-117.

25. Lima LC, Assis GV, Hiyane W, et al. Hypotensive effects of exercise performed around anaerobic threshold in type 2 diabetic patients. Diabetes Res Clin Pract. 2008;81(2):216-222.

26. Jones H, Pritchard C, George K, Edwards B, Atkinson G. The acute post-exercise response of blood pressure varies with time of day. Eur J Appl Physiol. 2008;104(3):481-489.

27. Simões GC, Moreira SR, Kushnick MR, Simões HG, Campbell CS. Postresistance exercise blood pressure reduction is influenced by exercise intensity in type-2 diabetic and nondiabetic individuals. J Strength Cond Res. 2010;24(5):1277-1284.

28. Ciolac EG, Guimarães GV, D’Ávila VM, Bortolotto LA, Doria EL, Bocchi EA. Acute aerobic exercise reduces 24-h ambulatory blood pressure levels in long-term treated hypertensive. Clinics (Sao Paulo). 2008;63(6):753-758.
29. Wallace JP, Bogle PG, King BA, Krasnoff JB, Jastremski CA. The magnitude and duration of ambulatory blood pressure reduction following acute exercise. J Hum Hypertens. 1999;13(6):361-366.

30. Taylor-Tolbert NS, Dengel DR, Brown MD, et al. Ambulatory blood pressure after acute exercise in older men with essential hypertension. Am J Hypertens. 2000;13(1 Pt 1):44-51.

31. Pescatello LS, Guidry MA, Blanchard BE, et al. Exercise intensity alters postexercise hypotension. J Hypertens. 2004;22(10):1881-1888.

32. Pescatello LS, Turner D, Rodriguez N, et al. Dietary calcium intake and renin angiotensin system polymorphisms alter the blood pressure response to aerobic exercise: a randomized control design. Nutr Metab (Lond). 2007;4:1.

33. Whelton PK, He J, Appel LJ, et al. Primary prevention of hypertension: clinical and public health advisory from The National High Blood Pressure Education Program. JAMA. 2002;288(15):1882-1888.

34. Hewitt JA, Whyte GP, Moreton M, van Someren KA, Levine TS. The effects of a graduated aerobic exercise programme on cardiovascular disease risk factors in the NHS workplace: a randomised controlled trial. J Occup Med Toxicol. 2008;3:7.

35. Rondon MUB, Alves MJ, Braga AM, et al. Postexercise blood pressure reduction in elderly hypertensive patients. J Am Coll Cardiol. 2002; 39(4):676-682.

36. Brum PC, Da Silva GJ, Moreira ED, Ida F, Negrao CE, Krieger EM. Exercise training increases baroreceptor gain sensitivity in normal and hypertensive rats. Hypertension. 2000;36(6):1018-1022.

37. Halliwill JR. Mechanisms and clinical implications of post-exercise hypotension in humans. Exerc Sport Sci Rev. 2001;29(2):65-70.

38. Halliwill JR, Minson CT, Joyner MJ. Effect of systemic nitric oxide synthase inhibition on postexercise hypotension in humans. $J$ Appl Physiol. 2000;89(5):1830-1836.

39. Moraes MR, Bacurau RF, Ramalho JD, et al. Increase in kinins on post-exercise hypotension in normotensive and hypertensive volunteers. Biol Chem. 2007;388(5):533-540.

40. Pontes FL Jr, Bacurau RF, Moraes MR, et al. Kallikrein kinin system activation in post-exercise hypotension in water running of hypertensive volunteers. Int Immunopharmacol. 2008;8(2):261-266.

41. Williamson JW, McColl R, Mathews D. Changes in regional cerebral blood flow distribution during postexercise hypotension in humans. J Appl Physiol. 2004;96:719-724.
International Journal of General Medicine

\section{Publish your work in this journal}

The International Journal of General Medicine is an international, peer-reviewed open-access journal that focuses on general and internal medicine, pathogenesis, epidemiology, diagnosis, monitoring and treatment protocols. The journal is characterized by the rapid reporting of reviews, original research and clinical studies across all disease areas.

\section{Dovepress}

A key focus is the elucidation of disease processes and management protocols resulting in improved outcomes for the patient.The manuscript management system is completely online and includes a very quick and fair peer-review system. Visit http://www.dovepress.com testimonials.php to read real quotes from published authors. 